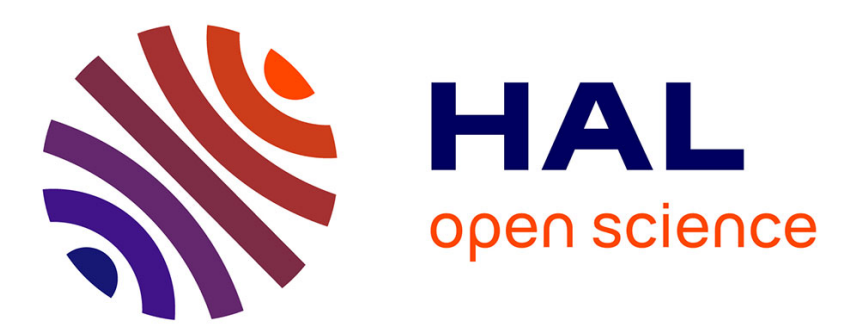

\title{
Collaborative Decision-making in Design Project Management. A Particular Focus on Automotive Industry
}

Marija Jankovic, Julie Stal-Le Cardinal, Jean-Claude Bocquet

\section{- To cite this version:}

Marija Jankovic, Julie Stal-Le Cardinal, Jean-Claude Bocquet. Collaborative Decision-making in Design Project Management. A Particular Focus on Automotive Industry. Journal of Decision Systems, 2010, 10.3166/jds.19.93-116 . hal-01216794

\author{
HAL Id: hal-01216794 \\ https://hal.science/hal-01216794
}

Submitted on 1 Jul 2016

HAL is a multi-disciplinary open access archive for the deposit and dissemination of scientific research documents, whether they are published or not. The documents may come from teaching and research institutions in France or abroad, or from public or private research centers.
L'archive ouverte pluridisciplinaire HAL, est destinée au dépôt et à la diffusion de documents scientifiques de niveau recherche, publiés ou non, émanant des établissements d'enseignement et de recherche français ou étrangers, des laboratoires publics ou privés. 


\title{
Collaborative Decision-Making in Design Project Management. A PARTICULAR FOCUS ON AUTOMOTIVE INDUSTRY
}

\author{
Journal of Decision Systems 9(1): 93-117.
}

Marija JANKOVIC, Julie STAL-LE CARDINAL, Jean-Claude BOCQUET

\begin{abstract}
New Product and Process Development (NPPD) in the automotive industry, integrated in large projects, focuses on producing vehicles while optimising performance (costs, quality, safety) and considerably reducing the "time to market". The first phase in NPPD is what we will call the "Project definition" phase. This phase is decisive because the project outcomes depend upon the success of this phase, i.e. capability to define ambitious and feasible objectives corresponding to the market. This phase is a collaborative decision-making phase. The two main research questions are: how to support collaborative decision-making in the early stages of NPPD, and what an adapted project management approach for these phases is. Research methodology used in this study is case-based using semi-structured interviews and participation/observation of working groups. The case study concerns 7 managers or engineers working in this phase and 9 vehicle development projects. The findings of this research point out the need for a new management paradigm and a proposition of a project management framework for the early stages of NPPD.
\end{abstract}

Keywords: New Product and Process Development, Collaborative decision-making, Collaborative decision Support, Early stages

\section{INTRODUCTION}

In complex technological projects, decisions are made collaboratively because none of the actors possesses the necessary knowledge to decide alone. Most of the decision-makers are field experts with different knowledge, background and objectives in the process.

We focused on the definition phase of the project objectives, which is, by definition, a phase where various sectors of the company (studies, purchases, industrialization, marketing, production) have to take collaborative decisions. The objective of our research is two-fold: identify elements relative to decision-making support, but also help in the management of decision-making processes.

Our contributions focus here on the understanding of the collaborative decisions in the design process of new products, as well as the management of the process within the project management framework.

The importance of decision-making has already been underlined by several research studies (Badke-Schaub and Gehrlicher 2003; Furini 2005; Hansen and Andreasen 2004). Whelton (Whelton, Ballard and Tommelein 2002) states that almost $80 \%$ of the product and process are specified in the early stages. Balbo (Balbo 1994) outlines the cost induced by the decision, and in the private study at Hewlett Packard identifies that a $\$ 1$ decision in the specification phase engages $\$ 600$ in the test phase or $\$ 6000$ in the usage phase. A similar experience is exposed by Pininfarina (Furini 2005). He underlines that a change of 1 euro in the specification phase correlates with around 1000 euros in the production phase. Bellut (Bellut 1990) confirms that a decision taken at the engineering stage will have 9 times greater impact than a decision in the manufacturing phase. 
Our research focuses particularly on the early stages of NPPD (New Product and Process Development). Our definition of NPPD is based on the work of several scholars (Lim 2003; Longueville 2003; Yannou, Jankovic and Nguyen Van 2008). After integration of field information and observation, the NPPD process can be schematised as below (Figure 1).

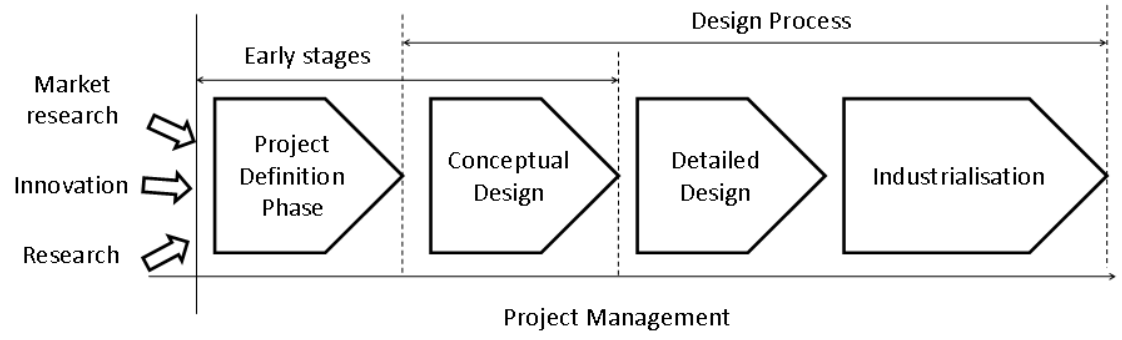

Figure 1: New Product Development Process

The Project Definition Phase begins when the client needs are identified in the market research and ends with the definition of the project objectives (cost, quality, delay, and product specifications). The characteristics of this phase are the participation of a large number of actors, who have different backgrounds and knowledge, and the high level of uncertainty concerning the future and the company's development capabilities. The Project Definition phase is also a phase where most of the strategic decisions concerning the project as well as the enterprise are defined through collaborative decision-making.

In order to address our research issues in the part 2 we propose a literature review concerning collaborative and cooperative decision support systems. Our research design as well as organization of our study is presented afterwards. In the part 4 of this paper we expose some conclusions of the research conducted in PSA Peugeot Citroen that permitted to determine some relevant causal factors relevant to our research questions. We propose a collaborative decision-making support model for the early stages of new product and process development in the part 5 of this paper, describing the information necessary to make decision. This model is used as a basis for a project management tool framework. The results of the implementation study are discussed in the part 7, and lead to some conclusions and possible future developments.

\section{RESEARCH LITERATURE}

Over the past two or three decades, organisations have been using information technologies for supporting business processes and decision-making (Kim, Godbole, Huang, Panchadhar and W. 2004). As for collaborative decision-making, the fields of group decision support systems and cooperative decision support systems (CSDS) have also been of interest for organisations (Zaraté 2005). The recent development of the world wide web have also been of interest for development of different applications, for example different consensus management techniques to develop a solution (Kim, Godbole, Huang, Panchadhar and W. 2004).

The definition of collaborative decision-making in the research literature is not uniform. Some of the work when speaking of collaborative decision-making considers distributed asynchronous decision-making (Aldunate, Pena-Mora and Robinson 2005; Chim, Anumba and Carrillo 2004; Cil, Alpturk and Yazgan 2005), 
which is often similar to the definition given for cooperative decision-making. Some research studies refer to it as multi-actor decision-making where actors have different goals (Karacapilidis and Papadias 2001; Panzarasa, Jennings and Norman 2002). In our research work, we are referring to this second definition of collaborative decision-making. Authors that come the closest to the definition adopted in this paper are Panzarasa (Panzarasa, Jennings and Norman 2002) and Karacapidilis (Karacapilidis and Papadias 2001).

Panzarasa and Jennings (Panzarasa, Jennings and Norman 2002) consider collaborative decision-making as a multi-agent socio-cognitive process. Thus they incorporate beliefs, goals, desires, intentions, and preferences in what they call mental modelling. The authors also adopt a prescriptive approach in order to give a set of possible actions at every step of collaborative decision-making. The model is developed using social mental shaping, the process by which the mere social nature of agents may impact upon their mental states and motivate their behaviour. Their collaborative decision-making model consists of four phases: the practical starting-point, group generation, social practical reasoning, and negotiation.

Karacapidilis and Papadis (Karacapilidis and Papadias 2001) consider collaborative decision-making to be an argumentation process. It is a process of "collaboratively considering alternative understandings of the problem, competing interests, priorities and constraints". Karakapidilis and Papadias (Karacapilidis and Papadias 2001) develop the "Hermes" system to support collaborative decision-making. In order to define Collaborative Decision Support Systems (CDSS) they use the Kreamer's definition (Kreamer and King 1988). They propose the Hermes systems a "generic active system that efficiently captures users' rationale, stimulates knowledge elicitation and argumentation on the issues under consideration, while it constantly (and automatically) checks for inconsistencies among users preferences and considers the whole set of the argumentation items asserted to update the discourse status".

Several scholars have underlined the characteristics of the collaborative decision-making process that we took into account in our research. Munkvold (Munkvold, Eim and Husby 2005) focuses on collaborative IS decisionmaking processes: "complex decision-making processes, involving multiple stakeholder groups". The authors present an analysis of collaborative decision-making processes related to the specification, selection and acquisition of a new IT solution for collaboration and information management. The challenges for using different collaborative technologies in the decision-making processes that were identified are: 1) ensuring the continuity in the project; 2) ensuring effective communication among different stakeholder groups and 3 ) gaining involvement and commitment from the business areas.

In order to build a decision support system, Hamel (Hamel, Pinson and Picard 2005) underlines the need to explicitly model behaviour including the interactions as well as the actions of the actors. The authors propose the use of a Multi-Agent Based Simulation (MABS) in order to take into account the interactions between individuals. This is because MABS has the ability to cope with simple entities as well as the organisations and interactions between entities and groups. The ACKA model that is proposed is based upon two principles: the definition of modelling and conceptual roles and a definition of the decision-making process as a series of interactions between stakeholders. 
Most of the research studies concerning collaborative decision-making, some of which are mentioned in this paper, are oriented to "decision support" in the collaborative environment with the goal of clarifying objectives and facilitating communication and information exchange. The goal of our research study is slightly different. Our research objective is to support collaborative decision-making with the goal of facilitating project management and control.

\section{ACTION RESEARCH METHODOLOGY}

The research presented study was undertaken in collaboration with the French car manufacturer, PSA Peugeot Citroën. PSA Peugeot Citroën has a significant market share of the European market. The company possesses two car brands: Peugeot and Citroën. In 2008, the group occupied $2^{\text {nd }}$ position in the European market with 1967100 vehicles Peugeot and 1461300 Citroën sold, representing 13.8\% of the European market. The company has also worldwide implantations in places such as Argentina, Brazil, Slovakia, the Czech Republic and Russia.

We adopted the action research approach in this study as discussed by Ottosson (Ottosson 2003). This approach is particularly adapted to the research concerning new product development processes. The research process that we followed in our research study can be resumed by steps given by Tabs and Noel (Tabs and Noel, 1997):

1. Identifying the problem;

2. Analysing the problem and determining some relevant causal factors;

3. Formulating tentative ideas about crucial factors and potential tools;

4. Gathering and interpreting data to sharpen these ideas and to develop action hypothesis;

5. Formulating action(s) and

6. Evaluating the results of actions.

This research study concerns vehicle development projects that can be considered big and complex: big because there are from 2000 to 5000 engineers participating in vehicle development and complex due to the number of interactions within the project. In general these projects have a long project time that can be between 2 and 4 years depending on the project. A sample of 7 vehicle development projects was chosen for data gathering. The choice of projects took into account differences in the size and type of vehicle developed (see table 2.1). We consider that the sample of 7 vehicle development projects is representative because it represents $40 \%$ of total projects conducted at the same time. 


\begin{tabular}{ccc}
\hline Vehicle Types & France & International \\
\hline Small Vehicles & 1 & 1 \\
Compact vehicles & 2 & 1 \\
Sedan & 2 & \\
\hline
\end{tabular}

Table 1: Data gathering sources

Data gathering for this research study was conducted through semi-open interviews and observations by the authors. In order to collect all the data in the phase four "Gathering and interpreting data to sharpen these ideas and to develop action hypothesis" we decided to interview at three levels: one person as Project Management Office Director; two people as Project Management Methodology Support Engineers; and 2 other people as Project Planners. These three roles are the key positions in project management and they represent: the planning, technical expertise required and the global overview of the project. The results of our research study are discussed in the part 7 of this paper.

\section{Collaborative decision-making model in the Product DeVelopment}

\subsection{Problem analysis and Relevant causal factors}

The mission of the project team in this phase is to define the coherent project objectives with regard to different constraints company constraints broadly defined including partners and collaborators, and the market). In order to do so, the team members are working with different company departments that determine the directions for future development on the one hand and the company's fields of expertise on the other.

At the very beginning of this phase, different company departments assign objectives that are necessary for the definition of project objectives to the project team. These departments include: marketing, production, innovation, strategy, development and design. The assigned company objectives represent the transcription of strategic orientations of the enterprise for different development fields. The project team has also to take into account the results of market segmentation and targeting and to integrate client needs (Figure 2).



Figure 2: Project objectives definition context 
The process of project objective definition is a very delicate one because of the difficulty of obtaining a balance between the company ambitions, representing the vision of the future, and the current know-how of the company. This balance is obtained and elaborated through the process of collaboration and negotiation, where project actors progressively converge the initial project definition to the precise definition of project objectives.

The complexity of this phase is underlined by several aspects that need to be managed (Jankovic, Bocquet, Stal Le Cardinal and Bavoux 2006):

- It is a phase where aspects of a project need to be defined, such as scope, planning, costs, quality,

- Project organisation and management are set up throughout the fulfilment of functions, assigned to every project team member,

- It is a phase of convergence of project objectives through the collaborative decision-making process,

- Management bases, as well as the motivation of project team, are built up progressively throughout this phase.

As we mentioned above, in complex projects the decisions are made collaboratively because none of the project actors possess the necessary knowledge to decide alone. The project actors that participate in the collaborative decision-making are experts and have different objectives in the decision-making process (Figure 3). As they have knowledge and information that result only from one field of product and process development (PPD), "their position in the decision-making process and their point of view is influenced by this knowledge". Another fact contributes to this position taking: the performance of one actor is evaluated upon his capability to attain the objectives that were assigned to him.

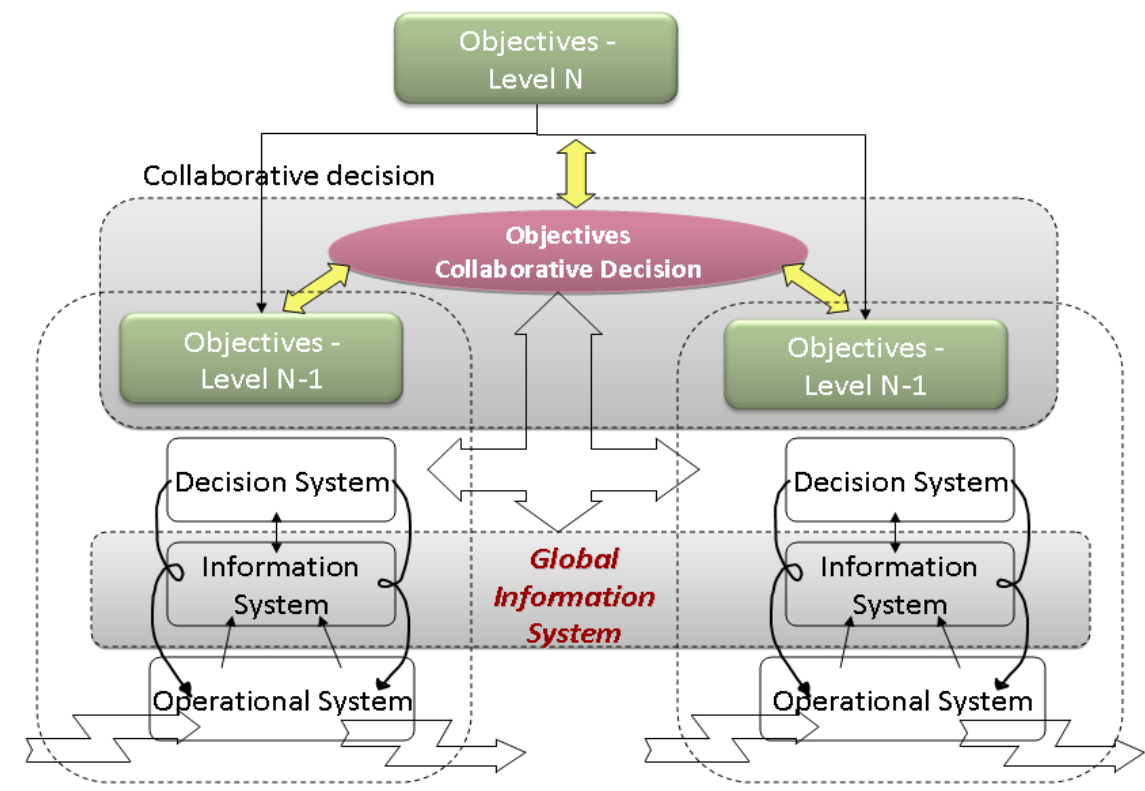

Figure 3: Collaborative Decision-Making System

The collaborative decision-making process in the PPD project is also a very important and efficient way to exchange opinion and information. Another advantage of this decision-making is that the opinion divergence and differences in problem definition influence the diversity and richness of generated alternatives and 
therefore the decision quality. This advantage of collaborative decisions is at the same time a source of major difficulties in a decision-making process. These difficulties include the following (Karacapilidis and Papadias 2001; Panzarasa, Jennings and Norman 2002):

- Different conflicts - for example between the objectives of the different actors participating in collaborative decision-making, preferences and strategies each may have related to their own objectives;

- Information acquiring problem - in the decision-making process the existence of too much or too little information concerning the problem, or relevant information missing;

- Influences of value judgment - These value judgements depend upon the role and goals of each actor.

The difficulties concerning project management and collaborative decision-making impact on several levels (Jankovic 2006) :

- Collaborative decision: The difficulties in identifying important decision elements: For example: who are the actors in the collaborative decisions, what is the information that the decision makers need to have at the moment of decision making, what is the level of criticality of information needed, what are the causes of the conflicts in collaborative decisions?

- Collaborative decision-making process: The difficulty to determine the impact of one collaborative decision further in the process, i.e. impact on other activities and decisions in the Project Definition Phase. For example: what the decisions to be made before and after are, what the decisions that will be influenced by the present collaborative decision are, i.e. what project objectives will be influenced and the activities influenced by this collaborative decision.

- Project: The difficulty in defining the activities and their sequencing in the Project Definition Phase as well as in controlling and piloting the project progress. For example: what needs to be done in order to define project objectives and what are the activities necessary to assure the coherence of project objectives?

\section{PROPOSITION OF THE COLLABORATIVE DECISION MAKING SUPPORT MODEL}

In order to support the decision-making process, we propose a model of collaborative decision-making. This model takes its roots from the systems thinking developed by Le Moigne (Le Moigne 1990). The goal of this model is to define the intrinsic elements of collaborative decisions in order to support the project team in the decision-making process and to enssure the quality of the decision. The global model is constituted of four views: Objectives, Process, Environment and Objectives. The Objectives view defines the objectives in the collaborative decision-making and the inter-relationships that influence their definition. The Process view concerns the prescriptive model of collaborative decision-making in order to assure the quality of the decision. The Environment view takes into account the information concerning the PPD process that can be seen as enterprise know-how. The Transformations view represents a follow up of different evolution states in collaborative decision-making. 


\subsection{Objectives View}

The Objectives view of the collaborative decision-making model concerns different objectives that influence the collaborative decision-making. This view also takes into account different relationships between objectives in collaborative decision-making.

The property of an objective is its recursiveness: "one project is decomposable on objectives, themselves decomposable on sub-objectives and so on, until the ultimate level accounting for elementary objective" (StalLe Cardinal 2000). The project decomposition process is complex and concerns the objectives of different enterprise levels. For example, in the objectives' decomposition process, the project team needs to explore relationships between objectives: to transcribe different enterprise objectives to project and product objectives, to decompose project objectives into sub-objectives and to study their feasibility through coherence verification. The difficulties of this process are:

- It concerns different objectives (enterprise, project and product), themselves concerning different organisation levels;

- These objectives are inter-related;

- The nature of the objective's relationships is not always known because of the constant need for innovation.

The collaborative decision-making objectives (Figure 4) are objectives of one collaborative decision that concern a common development field of two or more decision actors. The collaborative decision-making objectives concern two or more operational processes of PPD. These objectives represent an aggregation of the operational objectives of the concerned fields and are qualitatively different because they are expressed with different measurement units.

The objectives' decomposition process creates also a residue that cannot be integrated into operational objectives (level $\mathrm{N}-1$ ). Therefore, in most of the cases, the project management team considered operational objectives of the upper level as constraints in the decision-making process. The residue refers to the interfaces between domains.

$$
\operatorname{objN}=\operatorname{obj}_{1}(N-1)+o b j_{2}(N-1)+\text { Residue }
$$

objN = objectives defined for the level $N$ 


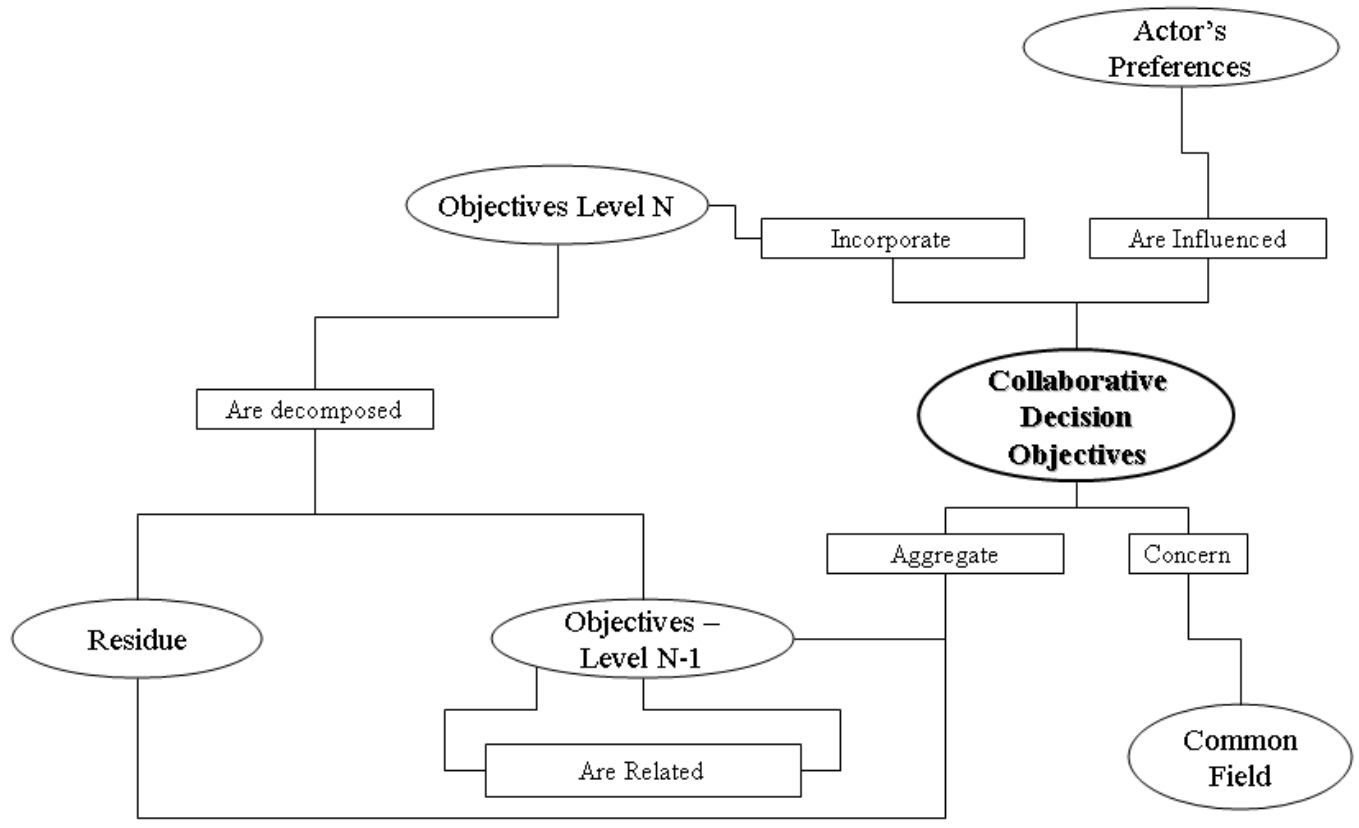

Figure 4: Objectives view in collaborative decision-making

Collaborative decision-making objectives are influenced by an actor's preference (Karacapilidis and Papadias 2001; Panzarasa, Jennings and Norman 2002). Each actor has preferences in the collaborative decision-making that are an expression of his competences and ambitions (Panzarasa, Jennings and Norman 2002). This influence is due to the evaluation system which is based upon the attainment of the objectives that are specifically assigned to the actor and not the global objectives on the project level. The evaluation is "result" based and generally very positive, but it can also create some problems. Lets take an example of the collaborative decision concerning vehicle design. This decision objective is to decide the design of the new vehicle taking into account the constraints of engineering and production. Decision-makers are: the design department, the design manager, the project manager, and representatives of different enterprise departments such as marketing and finance. The decision is to be taken in collaboration with the engineering department to ensure the feasibility of the design concept. In reality, the design department could consider design concepts and not to divulgate it because the emotional component can prevail even though the design does not correspond to budget or engineering constraints.

\subsection{EnVironment VieW}

The Environment view is a view that relates to relevant information concerning the development process and is considered as enterprise know-how. As our subject is collaborative decision-making in development projects, there are three different environments identified due to the project organisation: decision environment, project environment and enterprise environment (Figure 5). Each environment has a certain impact on the collaborative decision-making that is crystallised in the complex correlation with other environments. The environments are identified by its context, which is defined as the factors that influence the collaborative decision-making, and the actors working in these environments and of relevance for collaborative decisionmaking process. These three environments are correlated and the global context of collaborative decisionmaking can be identified only with great precision among all three of them. 




Figure 5: Environment view in Collaborative Decision-Making Model

The decision environment is constituted of the decision context and decision actors. In the decision context, based upon different studies related to different factors of influence or antecedents (Aldag and Fuller 1993; Esser 1998; Janis 1971; Louafa 2004; Panzarasa, Jennings and Norman 2002) and the factors that were observed and validated on the field research, we have identified three factors that have an impact on the collaborative decision-making process:

- Decision-making risks,

- Uncertainties and

- Decision importance.

The homogenous vision concerning these three factors is important for collaborative decision-making. As collaborative decision-making is subject to different value judgments (Karacapidilis and Papadias 1998b; Karacapilidis and Papadias 2001), different decision-making criteria (De Michelis and Grasso 1994) and different decision objectives, it is necessary to "negotiate" or determine these factors in order to have a better vision concerning the problem. For example, the decision concerning vehicle design does not imply the same risks for the design department and for the engineering department. If a design department draws a sports car, with sharp lines and very close to the ground, for engineering department just a question of windshield concerns the risks of production techniques: is it possible to produce a windshield with high resistance and a high inclination angle?

In collaborative decision-making it is necessary to distinguish different actors and their roles in the decisionmaking process for better coordination and control. The decision actors are persons that participate in collaborative decision-making. Each actor has a precise role in the process according to the degree of participation, observed and identified on the field, in collaborative decision-making. In the observation of different development projects in PSA Peugeot Citroen, there are three distinguished roles in the decisionmaking: 
- Collaborative decision-making pilot,

- Decision makers and

- Contributors.

A decision making pilot is a person in charge of collaborative decision-making, i.e. the decision in question contributes to the definition of objectives within the domain of his responsibility. The pilot is also a person in the best position to define the values of factors of the decision context and has the authority in front of the project team for an overall acceptance of these values. Amongst other things he also manages the "residue" resulting from the project objectives' decomposition process. The decision makers are project members having knowledge and information necessary for collaborative decision-making. The contributors are project members detaining the information important for the clarification of certain aspects of the collaborative decision-making problem, but do not have the responsibility to decide on the solutions (the field of their expertise is not directly concerned).

In the project environment, the project context is mostly determined by the project typology. For example, certain decisions concerning innovation aspects do not carry the same importance in different circumstances the vehicle project has the objective to replace the vehicle with a large part of the market and influences the enterprise image or if the objective is to develop a vehicle for a new market niche. In the first case, innovation aspects are of most importance because the product differentiation will be made with regard to the innovation aspect, whilst in the second case it is important to develop a vehicle corresponding to customers' needs. In the project environment, actors constitute two different decision-making groups:

- Direct Project Influence Groups or

- Indirect Project Influence Groups.

Project Influence Groups are decision-making groups (Longueville 2003) that constitute the project. The terms direct or indirect refer to their implications in the collaborative decision-making process. If the decision is their responsibility and concerns the field that they are to develop, then we call these groups Direct Project Influence Groups. If the decision does not concern their field of development and the actors of these groups do not have the knowledge to decide upon the problem, we call them Indirect Project Influence Groups.

The enterprise environment concerns the strategic level of the enterprise and all departments working with the project on the PPD. In the company the mission of each department is to develop the strategic orientation on the project level and to assign them to the project team. Depending on the type of the project, some of them might have different importance in the new product and process development. Actors in the Enterprise Environment are members of the Enterprise Influence Groups.

\subsection{Process VieW}

The Process view is a view that defines the collaborative decision-making process with the objective to ensure the quality of the decision. The importance of well defined decision-making process in the case of group decision-making has been investigated and pointed out by several case studies (Courtright 1978; Kameda and 
Sugimori 1993; Neck and Moorhead 1995). The process that we propose is based upon research on decisionmaking process of Simon (Simon 1977) and Le Moigne (Le Moigne 1990) (Figure 6).

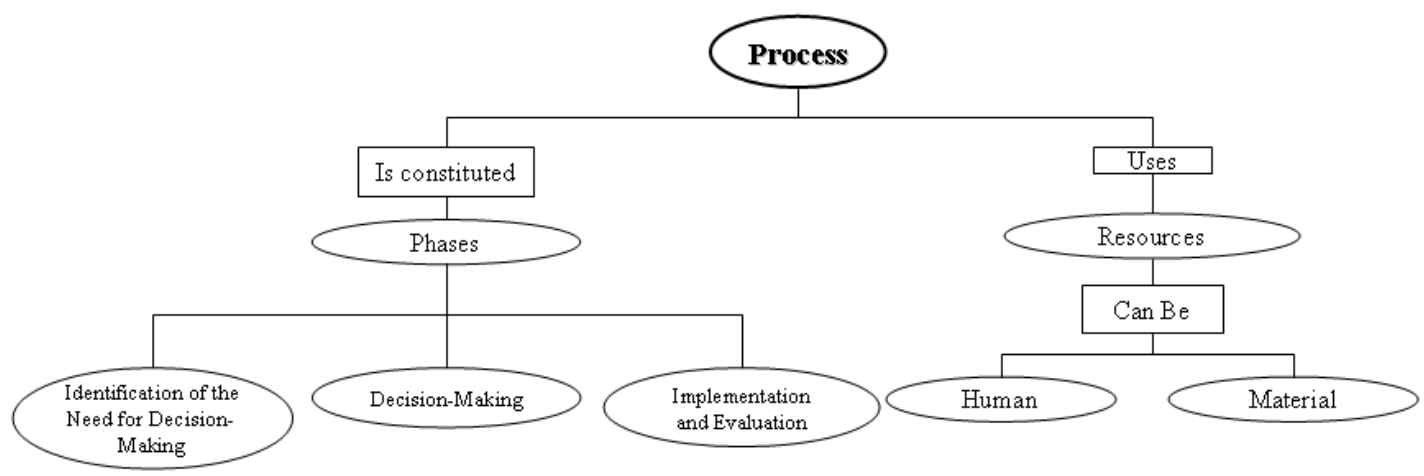

Figure 6: Process view

The Identification of the need for decision-making is an initial phase of the collaborative decision-making process. It starts when one of the actors identifies the problem that has to be treated with other collaborators and is blocking further progression of the development. Then the actor has to identify the pilot of this decision and the actors concerned. This is also a phase of the preparation for decision-making. In view of the decisionmaking process, every actor concerned prepares required information.

The decision-making phase is the negotiation phase. At the beginning it is of most interest to negotiate or discuss the objectives. Harrington (Harrington, Soltan and Forskitt 1995) states that the conflict can be anticipated if a situation is recognised as a source for potential conflict. This is the generation phase discussing possible solutions and reaching a consensus.

The Implementation and Evaluation phase is initiated with consensus reached concerning the solution. As in the model given by Le Moigne (Le Moigne 1990) there are several possible decision paths: decide to act according to the solution, decide to rethink about the solution, decide to get more information about the problem and decide to renegotiate the objectives. After the decision has been made, the project team has to elaborate the implementation plan for the given solution. This implementation plan is diffused to all actors concerned. The collaborative decision-making pilot is the person who organises regular feedback and if there is any problem in the implementation, there is a possibility to reiterate and initiate the first or the second phase.

\subsection{TRANSFormations VIEW}

The Transformations view represents a dynamic view of collaborative decision-making. If we consider the collaborative decision-making system given in the Figure 7, we can point out four transformations: 1) from operational system to information system, 2) from information systems to decision system, 3) from decision system to information system and finally 4) from information system to operational system. The transformations 1 and 2, shown in the Figure 7 are called the preparatory transformations because they contribute to the preparation of the collaborative decision-making. The implementing transformations are 3 and 4 because they are oriented to the implementation of the chosen solution. 


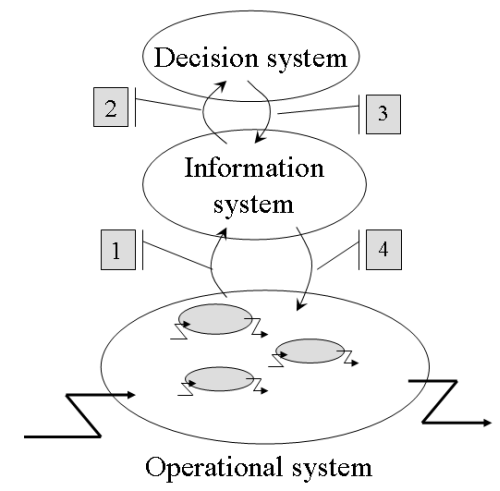

Figure 7: Different transformations $(1,2,3$, and 4$)$ in collaborative decision-making.

The preparatory transformations concern what is to be done in order to prepare the collaborative decisionmaking. They identify the necessary elements for the decision-making in the restricted sense. The preparatory transformations identify:

1. What should be done to prepare the collaborative decision-making: the required activities of the operational system enabling the decision-making;

2. What information is needed for quality decision-making: the information stocked in the information system.

Each of these transformations is specified so that the collaborative decision-making process follow-up is possible (Figure 8). Therefore, we observed that the first group of transformations is actually what we call the preparatory plan and is specified by:

- Activities: activities in different fields of the NPPD process that are to be accomplished.

- Responsibility: the role of person in charge of.

- Objective: the objectives of an activity.

- Criticality: the conjunction of the probability that the activity will be accomplished on time and the activity's importance for the decision-making.

The information that is stocked in the information system is characterised by:

- Name: the name of the information or the document containing the information.

- Responsibility: the role of the actor that is responsible for the information.

- Storage: the place where the information is stored and can be found.

- Criticality: the conjunction of the probability that the information will be provided on time and the importance of the information for the decision-making. 


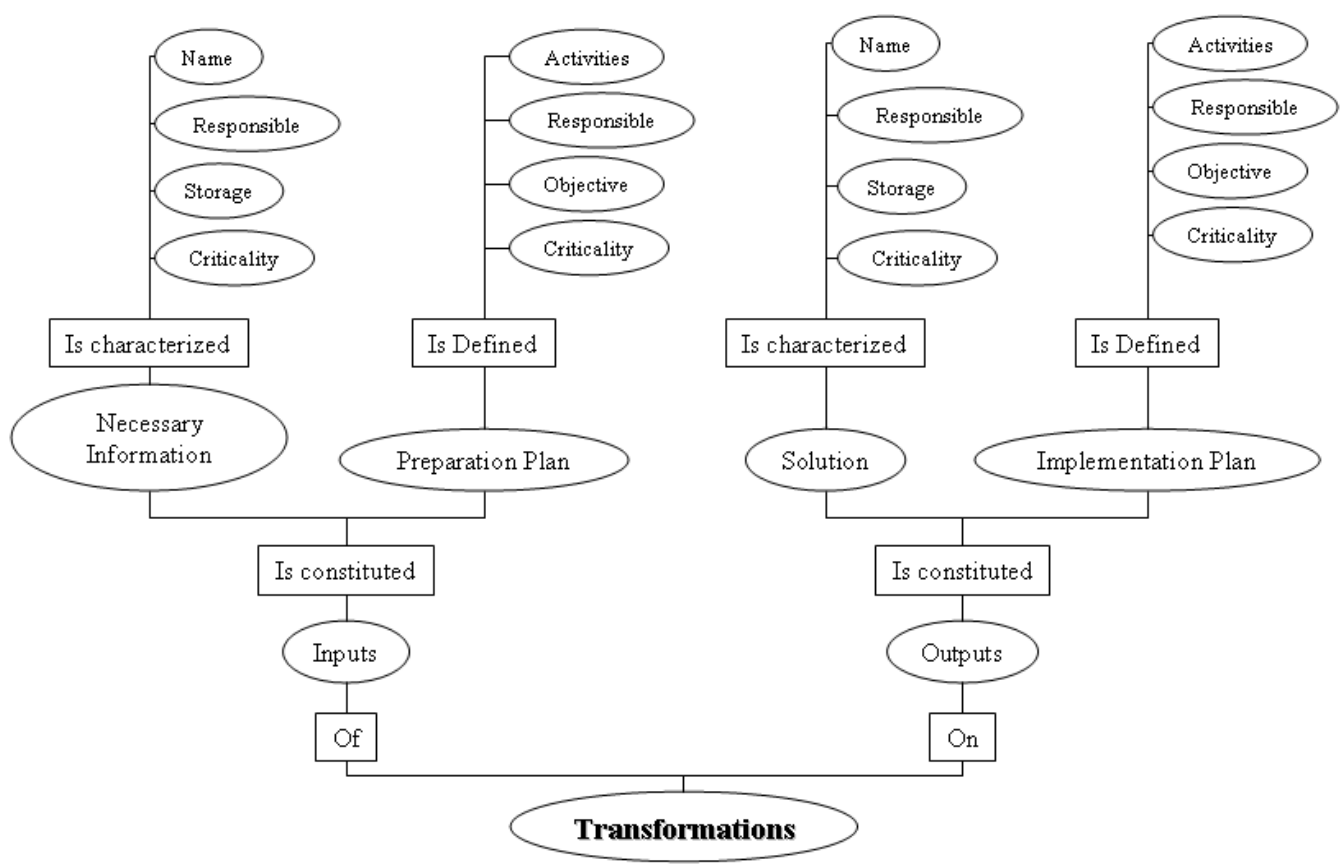

Figure 8: Transformation view

The implementing transformations concern what should be done in order to apply the chosen solution. Similarly to the preparatory transformations, the field observations point out that the implementing transformations concern:

- What has been decided in the decision system: the information that should be stocked in the information system;

- What should be done as a consequence of the chosen solution: the activities to be accomplished by the operational system?

The specification of these two transformations is the same as the ones that are preparatory transformations.

The objective of the Transformations view is to identify the impacts in the collaborative decision-making process. On the one hand the impacts on the collaborative decision and on the other impacts of the chosen solution decided during the collaborative decision.

\section{Project Management Tool Framework: Management of Collaborative Decision MAKIng Processes}

According to Baccarini (Baccarini 1996) some of the difficulties related to complex projects such as vehicle development projects, which influence project success, are the definition of project objectives and goals (Morris and Hough 1987) and project planning, coordination and control requirements (Baccarini 1996; Bubshait and Selen 1992; Melles, Robers and Wamelink 1990). 
The difficulty of project planning and coordination in the Project Definition Phase results from the incapacity to identify the possible activities for the completion of this phase. Moreover, the problem of project planning and coordination brings up the problem of project control. For example, the only existing control within this phase was possible at the very end of it, and on the upper management level, i.e. Senior Directors company level. During this phase, the project manager does not have any insight in the global project progress related to the convergence and coherence of project objectives and thus the possibility to introduce correction activities. The control point is at the end of this phase where project team obtains a "go or no go" decision from the top management. In the case of "no go" decision the time deadline for vehicle development is automatically increased. This augmentation can be up to several months, a delay which is not acceptable in current conditions where a global race for time reduction is ongoing. There is another danger concerning control problems. The Project Definition Phase influences and determines project success. If there is no control of the robustness of project objectives, the success of the whole project is at stake.

In the field research we identified two causes for the above mentioned difficulties: the first one concerns the current project management methodology and the other, collaborative decision-making. In the actual project management methodology, the recommended pattern to develop one project is to define in the first place the project scope, to develop a WBS and, based upon the WBS, to define the project activities and their sequencing, as well as different approaches used in project management (quality management, cost optimisation, risk management) (Project Management Institute 2004). The Project Definition Phase is a phase where the project objectives, i.e. the project scope, are to be defined. Therefore there is a need to find an approach in the early phases that helps define all aspects of one project. The second cause of difficulties in project planning is that the Project Definition Phase is a collaborative decision-making phase. The project complexity imposes actors' collaboration in the decision-making process. The collaborative decisions are made by different actors that participate in the project objectives definition process and in this process they have different and often opposite objectives. One of the examples of this conflict is a decision concerning design of the Peugeot 407. The project team had a choice between two different designs, a strong design with sport lines and less space at the back of the vehicle or a design like Renault Velsatis with more space behind. In the project every actor is responsible for one part or aspect of the vehicle development and thus has vision and knowledge "coloured" by the information of his/her own field. They also have different priorities concerning the decision values and alternatives. Hence, collaborative decision-making represents a rich way for the generation of decision alternatives and helps the project team in the identification of decision impacts, but these advantages are also the source of potential problems.

The model of collaborative decision-making that we presented in part 2 of this paper is used to help and support the project team by identifying the intrinsic elements of one collaborative decision. This model is also a basis for the development of the project management tool framework that we afterwards deployed in the MS Project. 
Transformations

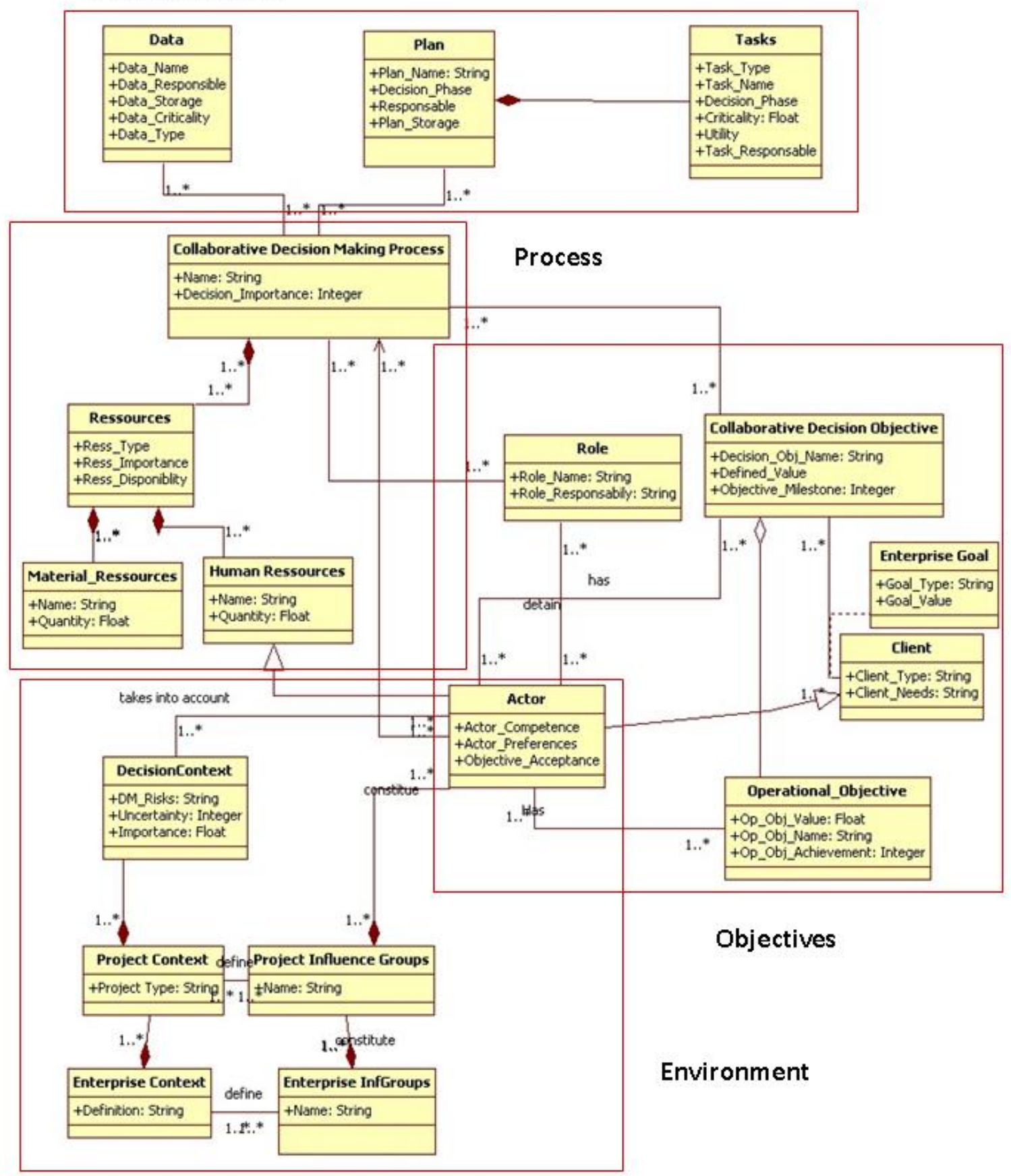

Figure 9: Class diagram - Individual File

Based upon the collaborative decision-making model we have capitalised the intrinsic information necessary to decision makers (Figure 9). In this work we propose a novel project management tool framework that uses the information of the UML model (Figure 10). 


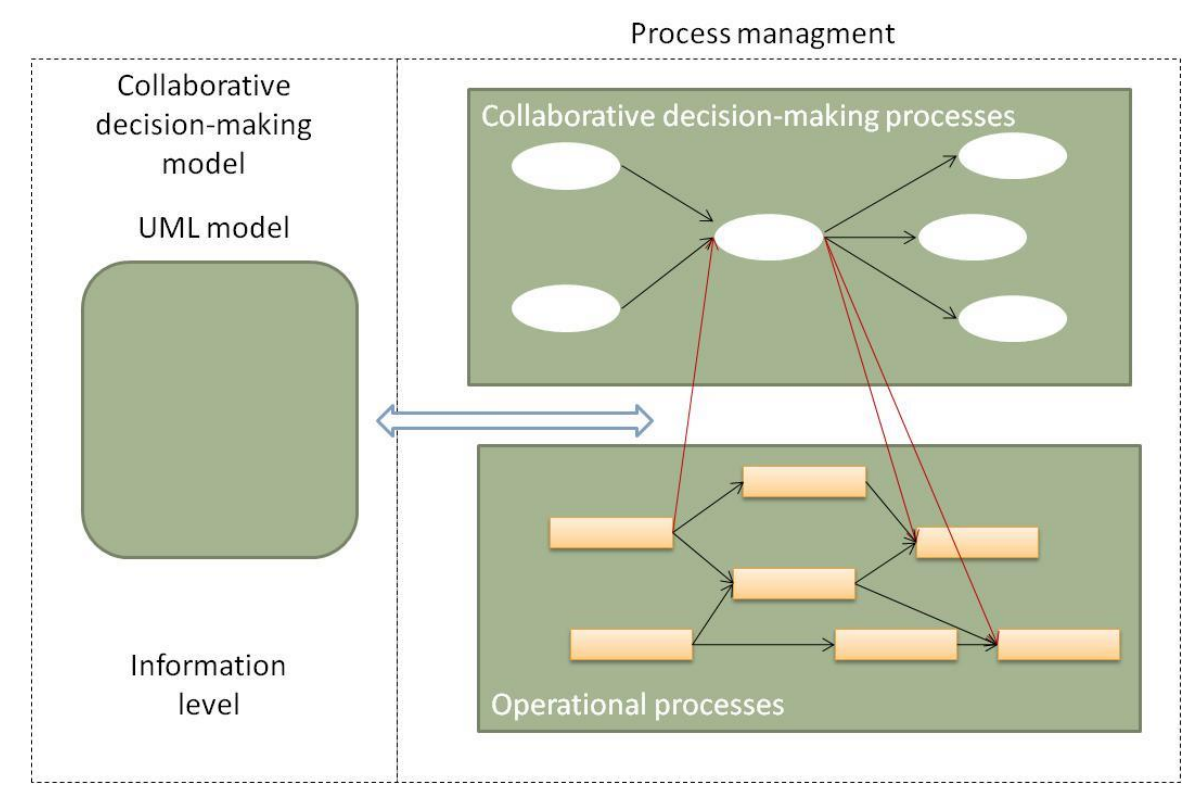

Figure 10: Project Tool Framework organisation

The structure of the project management tool framework consists of three levels: 1) the decisional level, 2) the information level and 3) the operational level. The decisional level concerns the collaborative decision-making processes in the NPPD process. These collaborative decision-making processes are represented by the sequence of different collaborative decisions. The relationships between collaborative decisions can be direct or indirect. They are direct when the output of one decision is the input of another and indirect when the output of one decision influences the input of another.

The collaborative decision-making processes contribute to the progressive definition of one project aspect or field, i.e. the project objectives in one project domain are progressively defined in this process. In our research we have not addressed the question of the classification of collaborative decision-making processes. Their definition was elaborated with regard to PSA Peugeot Citroen culture and know-how. For example, one of the processes is called "Purchase". This process concerns the definition of the supplier policies. It identifies the collaborative decisions to be made in order to define the project objectives in this field.

The Informational level concerns the information of one collaborative decision. This level is developed using the UML model (Figure 9). Based on this conceptual model, we have created a document called "the Individual File". The problems encountered in the implementation were the difficulty in information retrieving and extraction. For example, relationships between project objectives as well as their interdependencies are very difficult and complex to define. In the project development, team members use the current state of company knowledge to define them, but for the moment, there is no support containing explicit information. Future developments will consider this lack in order to improve and facilitate decision making for the project team.

The operational level concerns operational process of PPD. This level represents a classical view of PPD processes. The organisation of this level depends upon the organisations' culture and know-how. 


\section{IMPLEMENTATION RESULTS AND DISCUSSION}

The proposed project management framework is developed using Microsoft Project software because most of the project planners are already using this software. The proposed framework (cf. Figure 10) represents an extremely rich information base for the vehicle development projects. Operational processes consist of more than 800 macro activities. We point out 13 collaborative decision-making processes and on the information level we identify 73 collaborative decisions concerning the tactical and strategic level of the company. In order to integrate these two new functionalities (collaborative decision making model and collaborative decisionmaking processes), we have created a separate view in already used project management tool. This view reflects the actual collaborative decision making strategy of the company.

This tool allows the team project to:

- manage the project in the objectives definition phase,

- follow the global progress in this phase,

- have clearer visibility of the convergence of the objectives,

- $\quad$ organize the collaborative decision-making processes.

In order to test and evaluate the Project Management tool, we decided to follow up the users, i.e. the Project Planners, for a period of two months. The two month period is a representative time frame, but we cannot give any percentage because the duration of the phases represents a considerable strategic advantage of one company and is therefore confidential information. We selected 3 vehicle development projects, of differing size. The data was gathered through open interviews concerning several issues: facility of use, possibility to manage the collaborative decision impacts and the support in collaborative decision-making processes. The project planners underpinned several advantages of the developed tool:

- The tool gives a strong advantage in the construction of the project trajectory and its organisation in the early stages of NPPD, like the Project Definition Phase. The global project collaborative decision-making process presents a global overview of the phase progress. The crucial points to be resolved are identified in this tool.

- The tool also contributes to the identification of activities to be realised including the project planning and control.

- The three different levels of the tool and therefore the granularity of the representation constitute a complementary and coherent project overview. The central point that permitted us to identify and homogenise the information from different sources is the collaborative decision modelling used to create the information view. The advantage is that each actor possesses a coherent vision of the project and its progress.

Nevertheless, this implementation has also some limits that were underpinned:

- Interactivity can be better: The implementation of the tool in MS Project has as a consequence restricted interactivity. The links between processes, decisional, informational and operational, are manual, so the user has to know exactly what to do. 
- Knowledge management: in general, there is more than one project at any time. The new information, activities or decisions concerning one project have to be introduced manually in the reference tool. This is an important issue because there is a possibility that enterprise know-how will be lost because of the great quantity of information.

- Manipulation of elements other than activities or milestones: In Microsoft Project there is only a possibility to introduce activities or milestones. So when introducing the decisions, we had to be very prudent because of possible confusion. That is why in PSA Peugeot Citroën one person is responsible for project support in the utilisation phase.

- Integration of the dynamic aspect of decision-making: Even though the collaborative decisionmaking process integrates the dynamic aspect of one decision, this aspect is not incorporated in the tool.

\section{CONCLUSIONS}

The collaborative decision making is a major preoccupation in New Product and Processes Development. In this research we underline several findings and difficulties of collaborative decision-making as well as project management in the early stages of vehicle development projects. A sample of 7 vehicle development projects has been taken into account, of different size and type. Several of our findings point out the impossibility managing the early stages if the collaborative decision making processes are not supported and managed as well. In order to support the project team, we propose a global project management framework based upon the management of collaborative decision-making processes. The proposed framework contains three different levels: decisional, informational and operational.

Our model and its implementation in a tool contribute to the improvement of the robustness and the traceability of the process of collaborative decision-making (Jankovic 2006). The model allows unnecessary elements for the decision-making to be identified: who decides, on which elements, what it is necessary to know to be capable of taking the decision, what influences the decision. We also contribute to traceability by identifying various streams (decision-making, informative and operational) in the collaborative decisionmaking.

The implementation phase of two months on three different vehicle projects showed that the utilisation of the tool helps the project managers and project planners to organise the early stages, to manage causal relationships and feedback in the early stages, to support collaborative decision-making of the whole team and therefore to help the project team to attain convergence of project objectives. However, the tool was not tested on different types of projects and in different industries. The development of the tool is extremely demanding in time and it still to be tested to ascertain whether the tool is adapted to medium and small projects that are not necessarily high tech.

Finally, our study has pointed out the need to further develop the project management methodology which is poorly adapted to early stages. We think that the problems identified give an opening for the development of 
different approaches in project management. For example, to create a new way for project organizing and control based on identifying the decisions to be made and their correlation to the project objectives definition, therefore improving the performance indicators. This study has identified a great operational need for the information and identification of necessary elements for good decision-making. We think that the development of the exhaustive collaborative decision-making supporting system may be a more sustainable solution for project management and project team during the project in order to inform the collaborative decision making process and prepare the project team members for this important activity.

\section{REFERENCES}

1. Aldag, R. J. and S. R. Fuller (1993). "Beyond Fiasco: A Reappraisal of the Groupthink Phenomenon and a New Model of Group Decision Processes." Psychological Bulletin 113(3): 533-552.

2. Aldunate, R., F. Pena-Mora and G. Robinson (2005). "Collaborative distributed decision making for large scale disaster relief operations: Drawing analogies from robust natural systems." COMPLEXITY 11(2): $28-38$

3. Baccarini, D. (1996). "The concept of project complexity - a review." International Journal of Project Management 14(4): 201-204.

4. Badke-Schaub, P. and A. Gehrlicher (2003). Patterns of Decisions in Design: Leaps, Loops, Cycles, Sequences and Meta- processes. International Conference on Engineering Design - ICED 03, Stockholm.

5. Balbo, S. (1994). Evaluation érgonomique des interfaces utilisateurs: un pas vers l'automatisation. Grenoble, Université Joseph Fournier - Grenoble 1.

6. Bellut, S. (1990). La compétitivité par la maîtrise des coûts. Conception à coût objectif et analyse de la valeur.

7. Bubshait, K. A. and W. J. Selen (1992). "Project characteristics that influence the implementation of Project management techniques: a survey." Project Management Journal 23(2): 43-46.

8. Chim, M. Y., C. J. Anumba and P. M. Carrillo (2004). "Internet-based collaborative decision-making system for construction." Advances in Engineering Software 35(6): 357-371.

9. Cil, I., O. Alpturk and H. R. Yazgan (2005). "A new collaborative system framework based on a multiple perspective approach: InteliTeam." Decision Support Systems

10. Courtright, J. A. (1978). "A Laboratory Investigation of Groupthink." Communication Monographs 45(3): 229-246.

11. De Michelis, G. and M. A. Grasso (1994). Situating conversations within the language/action perspective: the Milan Conversation Model. CSCW'94 Conference, New York, ACM Press.

12. Esser, J. K. (1998). "Alive and Well after 25 Years: A Review of Groupthink Research." Organizational Behavior and Human Decision Processes 73(2-3): 116-141.

13. Furini, P.-F. (2005). Collaborative Design And Learning. 
14. Hamel, A., S. Pinson and M. Picard (2005). A new approach to agency in a collaborative decisionmaking process. International Conference on Intelligent Agent Technology.

15. Hansen, C. T. and M. M. Andreasen (2004). A Mapping of Design Decision Making. International Design Conference - Design 2004, Dubrovnik.

16. Harrington, J. V., H. Soltan and M. Forskitt (1995). "Negotiation in a Knowledge-Based Concurrent Engineering Design Environment." Expert Systems 12(2): 139-147.

17. Janis, I. (1971). "Groupthink." Psychology today: 43-46.

18. Jankovic, M. (2006). Collaborative decision making in new product development. Application to the car industry. Industrial Engineering Laboratory. Paris, Ecole Centrale Paris.

19. Jankovic, M., J.-C. Bocquet, J. Stal Le Cardinal and J.-M. Bavoux (2006). Integral Collaborative Decision Model in order to Support Project Definition Phase Management. International Design Conference Design 2006, Dubrovnik, Croatia.

20. Kameda, T. and S. Sugimori (1993). "Psychological entrapment in group decision making : an assigned decision rule and a groupthink phenomenon." Journal of personality and social psychology 65(2): 282292.

21. Karacapidilis, N. and D. Papadias (1998b). "A Computational Approach for Argumentative Discourse in Multi-Agent Decision Making Environments." Al Communications Journal 11(1): 21-33.

22. Karacapilidis, N. and D. Papadias (2001). "Computer supported argumentation and collaborative decision making: the HERMES system." Information Systems 26(4): 259-277.

23. Kim, S.-y., A. Godbole, R. Huang, R. Panchadhar and S. W. W. (2004). Toward an integrated humancentered knowledge- based collaborative decision making system. IEEE INTERNATIONAL CONFERENCE ON INFORMATION REUSE AND INTEGRATION.

24. Kreamer, K. L. and J. L. King (1988). "Computer-based systems for cooperative work and group decision making." ACM Computing surveys 20(2): 115-146.

25. Le Moigne, J.-L. (1990). La modélisation des systèmes Complexes. Paris, Dunod.

26. Lim, D. (2003). Modélisation du processus de conception centrée utilisateur, basée sur l'intégration des méthodes et outils de l'ergonomie cognitive: Application à la conception d'IHM pour la télévision interactive. Ile de France, ENSAM.

27. Longueville, B. (2003). Capitalisation des processus des décisions dans les projets d'innovation: Application à l'automobile. Industrial Engineering Laboratory. Paris, Ecole Centrale Paris.

28. Louafa, T. (2004, Mai 2004). "Processus de décision en management de projet integré." Retrieved Mai 2004.

29. Melles, B., J. C. B. Robers and J. W. F. Wamelink (1990). A typology for the selection of management techniques in the construction industry. CIB 90 Conference Building Economics and Construction Management, Sydney.

30. Morris, P. W. G. and G. Hough (1987). The Anatomy of Major Projects: a study of the reality of project management, John Wiley \& Sons. 
31. Munkvold, B., K. Eim and O. Husby (2005). "Collaborative IS decision- making: Analyzing decision process characteristics and technology support." LECTURE NOTES IN COMPUTER SCIENCE 3706: 292307.

32. Neck, C. P. and G. Moorhead (1995). "Groupthink Remodeled: The Importance of Leadership, Time Pressure, and Methodical Decision-Making Procedures." Human Relations 48(5): 537-557.

33. Panzarasa, P., N. R. Jennings and T. J. Norman (2002). "Formalizing collaborative decision-making and practical reasoning in multi-agent systems." Journal of Logic and Computation 12(1): 55-117.

34. Project Management Institute, P. (2004). A Guide To The Project Management Body Of Knowledge.

35. Simon, H. A. (1977). The New Science of Management Decisions. Englewood-Cliffs, Prentice hall.

36. Stal-Le Cardinal, J. (2000). Etude des dysfonctionnements dans la prise de décision. Application au choix d'acteur. Industrial Engineering Laboratory. Paris, ECP.

37. Whelton, M., G. Ballard and I. D. Tommelein (2002). "A Knowledge Management Framework for Project Definition." Electronic Journal of Information Technology in Construction -ITcon 7: 197-212.

38. Yannou, B., M. Jankovic and T. Nguyen Van (2008). Diversité industrielle de déploiement des projets de conception. La conception industrielle de produits. Paris, Hermès-Lavoisier. Volume 2 : spécifications, déploiement et maîtrise des performances.

39. Zaraté, P. (2005). Des Systèmes Interactifs d'Aide à la Décision aux Systèmes Coopératifs d'Aide à la Décision. Toulouse, Institut National Polytechnique de Toulouse. 